Przhedetskiy Yury Valentinovich, Ph.D. (Med.), Professor, Honored doctor of the Russian Federation, head of the Department of reconstructive plastic and oncology, Rostov Cancer Research Institute (63, 14 line, Rostov-onDon, 344037, Russian Federation). E-mail: yurypr@gmail.com

Przhedetskaya Natalia Vitovna, Doctor of Economics, professor of Economic Theory department, Rostov state economic university (RINH) (69, B. Sadovaya St., Rostov-on-Don, 344002, Russian Federation). E-mail: nvpr@bk.ru

Shevelyova Veronika Vladimirovna, Candidate of Economic Sciences, associate professor "The economic theory", Rostov state economic university (RINH) (69, B. Sadovaya St., Rostov-on-Don, 344002, Russian Federation). E-mail: beloveronika @yandex.ru

\title{
MARKETING OF HEALTHCARE ORGANIZATIONS IN THE CONTEXT OF NATIONAL PROJECTS ON THE EXAMPLE OF CANCER SERVICE Abstract
}

The formation and development of marketing of medical organizations in modern Russia are characterized by such trends, which are manifested in a more active promotion of medical organizations, medical products and services, medical workers. At the same time, at all stages of marketing activities, there are many problems associated with the lack of investment resources and lack of flexibility of public health organizations, as well as consumer distrust and low price competitiveness of private health organizations.

Keywords: health care, medical organization marketing, medical services, private and public medical organizations, market segmentation, marketing complex, medical services, competitiveness, living standards of the population.

\section{References}

1. Ignatova T.V., Ashirova M.N. Obshchestvennye blaga i gosudarstvennye uslugi // Vestnik Volgogradskogo gosudarstvennogo universiteta. Seriya Ekonomika. Ekologiya. 2015. № 2. P. 7 - 17.

2. Kostanyan A.A. Klientoorientirovannost' v gosudarstvennom zdravoohranenii: vozdejstvie na uroven' udovletvorennosti pacientov // Marketing v Rossii i za rubezhom. 2018. № 1. P. 7 - 13.

3. Savel'eva N.A., Kovalenkova O.G., Simonyan T.V. Sovremennye tendencii razvitiya sfery medicinskih uslug na primere Severo-Kavkazskogo federal'nogo okruga // Nauka i obrazovanie: hozyajstvo i ekonomika; predprinimatel'stvo; pravo i upravlenie. 2019. № 1 (104). P. 13 - 18.

4. Reznik G.A. Strategiya pozicionirovaniya kompanii na osnove social'no-marketingovoj programmy // Marketing v Rossii i za rubezhom. 2019. № 5. P. 10 - 15.

5. SHeresheva M.YU., Kostanyan A.A. Klientoorientirovannost' personala v gosudarstvennyh organizaciyah zdravoohraneniya Rossii // Vestnik Sankt-Peterburgskogo universiteta. Ser. 8. Menedzhment. 2015. № 4. P. 74 - 114.

\section{УПРАВЛЕНИЕ ИННОВАЦИОННЫМ ПОТЕНЦИАЛОМ АГРОПРОМЫШЛЕННОГО КОМПЛЕКСА: РЕНТНЫЙ ПОДХОД}

\author{
Хейфич \\ Борис \\ Игоревич \\ кандидат экономических наук, доцент, Липецкий казачий институт технологий \\ и управления (филиал) Московского государственного университета технологий \\ и управления им. К.Г. Разумовского (ПКУ) (398006, Россия, г. Липецк, \\ ул. Краснознаменная, 4). E-mail: b.heifits@yandex.ru
}

\section{Аннотация}

В статье рассмотрен процесс управления инновационным потенциалом агропромышленного комплекса с точки зрения рентного подхода. Автором исследовано влияние голландской болезни на инновационный потенциал АПК, выявлены различия между действительным и фиктивным капиталами. Проведены исследования производственно-генетического потенциала решения проблемы импортозамещения и реиндустриализации АПК РФ. В результате предложено инновационным дифференциальным рентным доходом называть избыток над среднеотраслевой прибылью в АПК за счет дополнительно вложенного капитала в инновационную деятельность и сформировано авторское представление о факторах, формирующих инновационную дифференциальную ренту как результата функционального управления инновационным потенциалом АПК.

Ключевые слова: инновационный потенциал, агропромышленный комплекс, рентный доход, инновационный дифференциальный доход, рентные отношения, земельная рента, конкурентоспособность производства, производительность труда, организационно-технические инновации.

Радикальные изменения в ресурсной и организационной основах современной экономики коренным образом изменили классические представления о видах ренты и сущности рентных отношений в сельском хозяйстве. Без инновационного развития невозможен процесс импортозамещения, что прежде всего является направлением экономической политики любого государства [15].

Если говорить об эволюции исследований социально-экономической сущности и природы земельной ренты с точки зрения инновационного развития агропромышленного комплекса то, тем 
не менее, нельзя не вспомнить труды Д. Рикардо, который считал, что образование ренты обусловлено не только и не столько природными факторами, сколько необходимостью вовлекать в сельскохозяйственный оборот земли худшего качества вследствие ограниченности хороших и лучших земель.

Рикардо, труды которого сохраняют свою актуальность и в настоящее время утверждал: «Рента - создание ценности, а не создание богатств» $[1,5],-$ постулируя тем самым, что источник ренты - не характеристики земель (плодородие), а труд сельскохозяйственных рабочих. Но одни и те же трудовые усилия на более плодородных землях дают больший, по сравнению с худшими землями. Реализация этой продукции позволяет собственнику земли получить рентный доход. Стратегия развития во многом определяется сценарием изменения общей бизнес-среды [6].

Развитие теории ренты К. Марксом ввело в научный оборот категории абсолютной и дифференциальной ренты.

Абсолютная рента имеет внеотраслевой характер: причина ее образования заключается в монополии частной собственности на землю, а условие образования обусловлено относительно (по сравнению с промышленностью) низким органическим строением капитала. Дифференциальная рента I образуется вследствие ограниченности лучших земель, более плодородных и расположенных более удобно для потребителя продукции, условием ее образования является собственность на лучшие земли.

Дифференциальная рента II порождается мероприятиями по повышению плодородию, в результате которых формируется дополнительная прибыль. Собственник участка, повышая плату за пользование участком с улучшенными характеристиками, получает дифференциальную ренту II. Соответственно, обладание худшими участками либо стимулирует инновационную активность собственника или арендатора как инструмента обеспечения среднерыночной доходности на вложенной капитал, либо, в противоположном случае, ведет к разорению арендатора и ликвидации неэффективного актива собственником. Поэтому владельцы лучших земель в меньшей степени заинтересованы в инновационном развитии как вследствие образования абсолютной ренты и дифференциальной ренты I; условием конкурентоспособности производства на худших участках является стремление владельцев или арендаторов к получению дифференциальной ренте II. На основании приведенных аргументов можно утверждать, что формирование инновационного потенциала агропромышленного комплекса зависит от возможности получения собственниками факторов сельскохозяйственного производства абсолютной ренты и дифференциальной ренты I, а использование инновационного потенциала определяется мотивацией к получению дифференциальной ренты II.

В специальной литературе отмечается обратная связь доступности благ, извлекаемых из природных ресурсов, и технологического прогресса: чем выше интенсивность использования природных ресурсов и чем большую рентабельность эта деятельность обеспечивает, тем выше вероятность технологического отставания и тем ниже темпы инновационной активности. Об этом пишут, например, А.С. Семенов и Е.А. Дерунова: «Еее одним возможным объяснением стабилизации технологического отставания и даже деиндустриализации в ряде стран являются искажения экономики, возникающие из-за увеличения интенсивности разработки исчерпаемого природного ресурса, например, нефти или газа. Из-за более высокой рентабельности капитал начинает перетекать из наукоемких отраслей, обеспечивающих рост технологического уровня экономики в целом, в сектор добычи ресурса. Этот эффект может усугубляться тем, что в связи с ростом благосостояния населения, спрос на неторгуемый товар внутри страны увеличится, цены на него вырастут, и факторы производства будут перетекать также и в сектор неторгуемого товара. Эти два эффекта и представляют собой «голландскую болезнь», результатом которой становится угасание наукоемкого обрабатывающего сектора и усиление зависимости экономики от экзогенной цены на ресурсы» [12].

Голландская болезнь как экономический феномен в сельском хозяйстве обусловлено значительными площадями сельскохозяйственных угодий или земельных участков, потенциально пригодных для ведения сельского хозяйства и развития агропромышленного комплекса. Ведение сельскохозяйственного производства на лучших землях, дающих возможность получения дифференциальной ренты I, не создает стимулов для инновационной активности и, при прочих равных условиях, дестимулирует внедрение достижений научно-технического прогресса.

Напротив, условиям получения дифференциальной ренты II, является деятельность по улучшению плодородия земель, внедрение организационно-технических инновацией. Следовательно, ухудшение качества земли в агропромышленном комплексе региона является фактором, инициирующим инновационные изменения при производительном использовании ресурсов земледелия и животноводства. Поэтому в дальнейшем под инновационным потенциалом АПК будем понимать способность комплекса в целом и/или отдельных элементов, его составляющих, к изменениям, 
прогрессу и трансформации в новое состояние, обеспечивающее его конкурентоспособность по сравнению с прочими отраслями экономики.

Конкурентоспособность в контексте настоящего исследования понимается как возможность получения, по крайней мере, не меньшей по сравнению с другими отраслями экономики, прибыли на вложенный капитал. Эту возможность обеспечивает инновационная активность и образования дифференциальной ренты II.

Авторское представление о проявлении голландской болезни в сельском хозяйстве представлено на рис. 1. Краткосрочные эффекты голландской болезни проявляются в снижении производительности труда при неизменной и, может быть, растущей рентабельности производства за счет образования дифференциальной ренты II. Организационное-технические инновации ведут к высвобождению персонала и безработице.

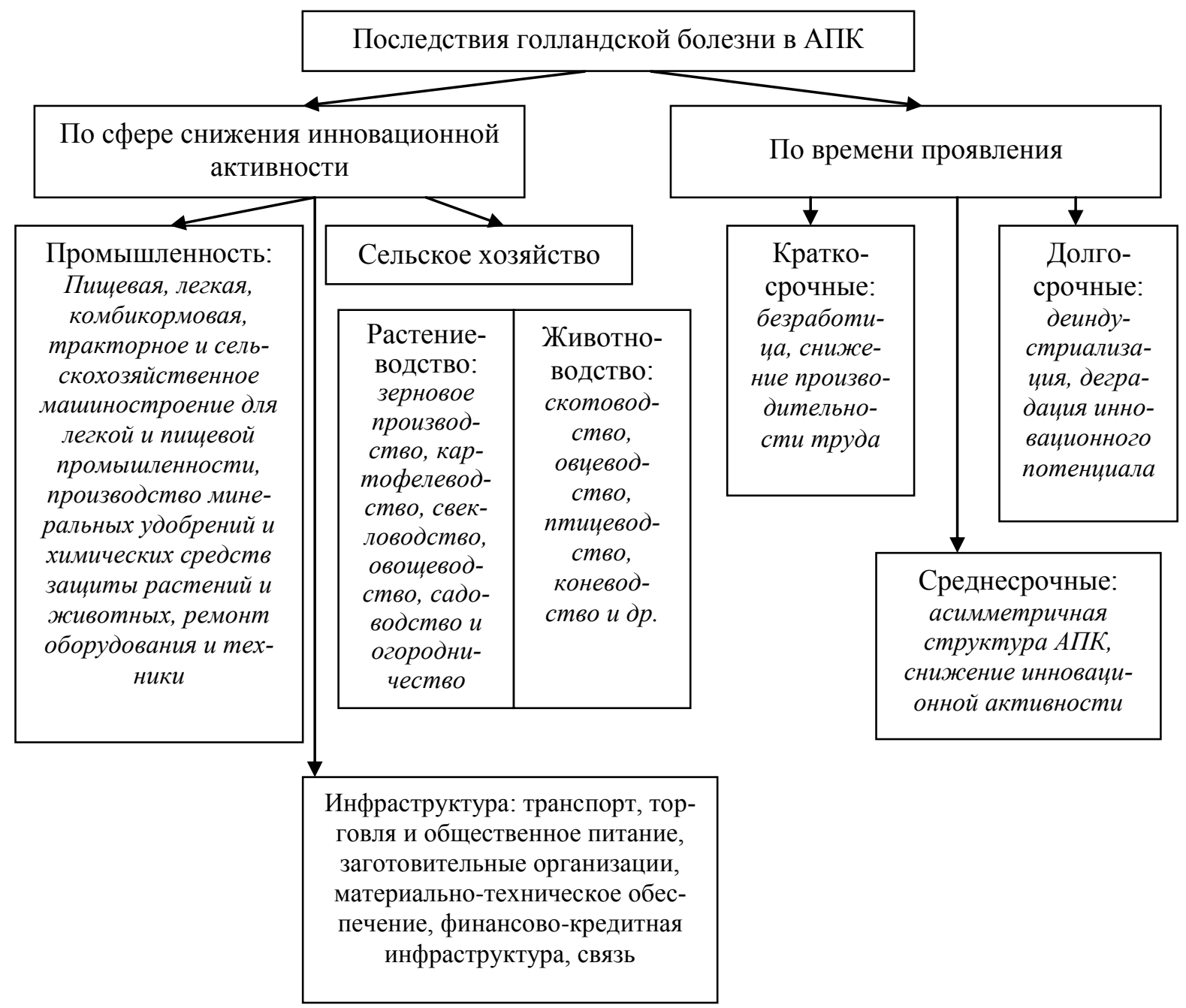

Рис. 1. Влияние голландской болезни на инновационный потенциал АПК (разработано автором на основе [14])

Одним из существенных отличий современной экономики от экономики XVIII - XIX вВ., когда А. Смит, Д. Рикардо и К. Маркс заложили основы и разработали теорию ренты, является формирование двух сегментов рынка:

- стоимостной или реальный, в котором функционирует действительный капитал, создается фактическая стоимость и формируется цена товара;

- рентный, в котором работает фиктивный капитал и может формироваться фиктивная стоимость [9, с. 297].

Различия между фиктивным и действительным капиталами отражены на рис. 2. 


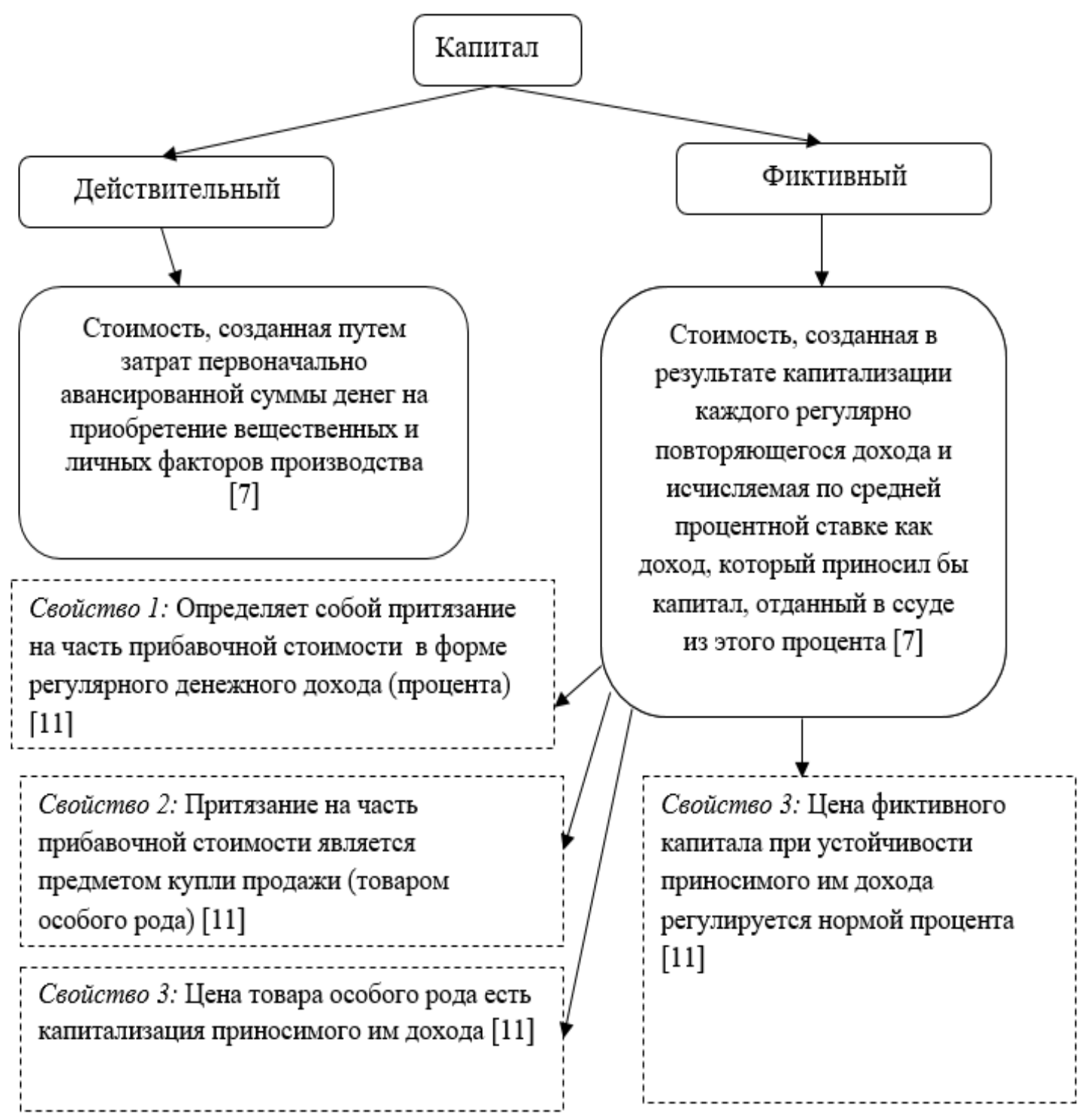

Рис. 2. Действительный и фиктивный капитал (составлено автором по [7, 11, с. 687])

Одной из важнейших причин деиндустриализации российской экономики в целом и агропромышленного комплекса в частности, а также же деградации инновационного потенциала АПК, является высокая доля фиктивного капитала [13].

Взаимосвязь между рентой и инновациями в сельском хозяйстве не исчерпывается только земельной рентой, но имеет более общий характер. Например, Е.М. Носкова фактором роста инновационной активности в сельском хозяйстве считает перераспределение ренты в добывающей промышленности [10].

Связь ренты и инновационного потенциала прослеживается в трудах ученых, занимающихся проблемами управления развитием АПК и его инновационным потенциалом. В частности, Г.А. Ефимова и О.В. Осипова, проводя исследования производственно-генетического потенциала решения проблем реиндустриализации и импортозамещения агропромышленного комплекса РФ, предложили концепцию рентного подхода к регулированию процесса воспроизводства генетического потенциала на уровне селекционно-генетических структур в связи с дифференциальной рентой II [4] (рис. 3). 


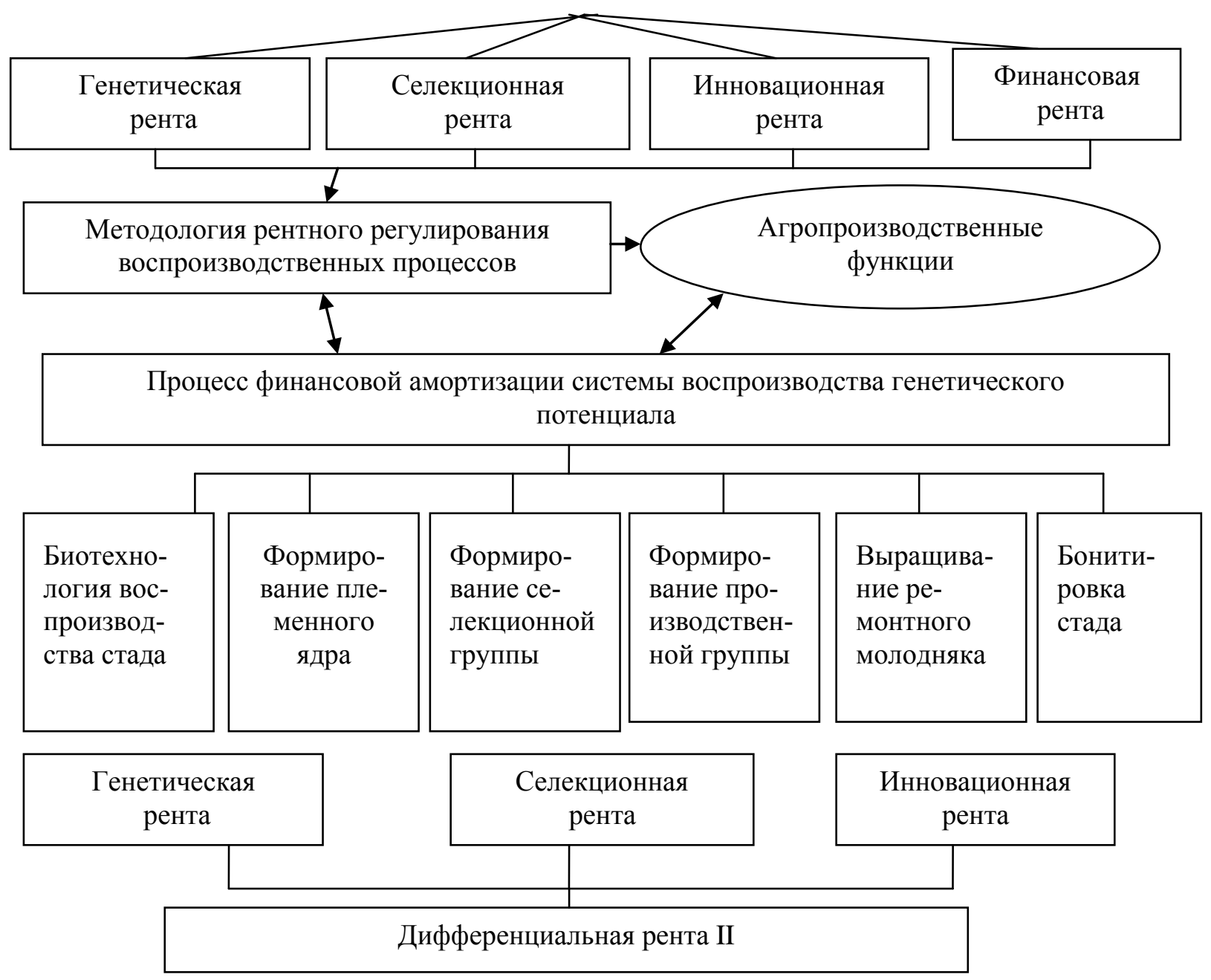

Рис. 3. Концепция рентного подхода к регулированию прощесса воспроизводства генетического потенциала на уровне селекционно-генетических структур [4]

Как следует из рис. 3, дифференциальная рента включает в себя инновационную ренту, и поэтому можно говорить, что инновации являются одним из факторов образования дифференциальной ренты II [3]. Тогда инновационным дифференциальным рентным доходом будем называть избыток над среднеотраслевой прибылью в АПК за счет дополнительно вложенного капитала в инновационную деятельность.

Инновационная рента в контексте настоящего исследования синонимичная понятию интеллектуальной ренты, что подтверждается и практикой. Так, обобщая итоги развития аграрного сектора Белгородской области за 2017 г., губернатор области подчеркивал, условием повышения конкурентоспособности сельскохозяйственного производства является получение так называемой интеллектуальной ренты как результата научных исследований и инновационной активности.

Интенсивным фактором повышения конкурентоспособности сельскохозяйственного производства является развитие и эффективное использование инновационного потенциала АПК. Развитие биотехнологий и получение биотехнологических продуктов - еще одно важнейшее направление отрасли. [2].

На рис. 4 представлена авторское представление о факторах, формирующих инновационную дифференциальную ренту как результата функционального управления инновационным потенциалом АПК. 


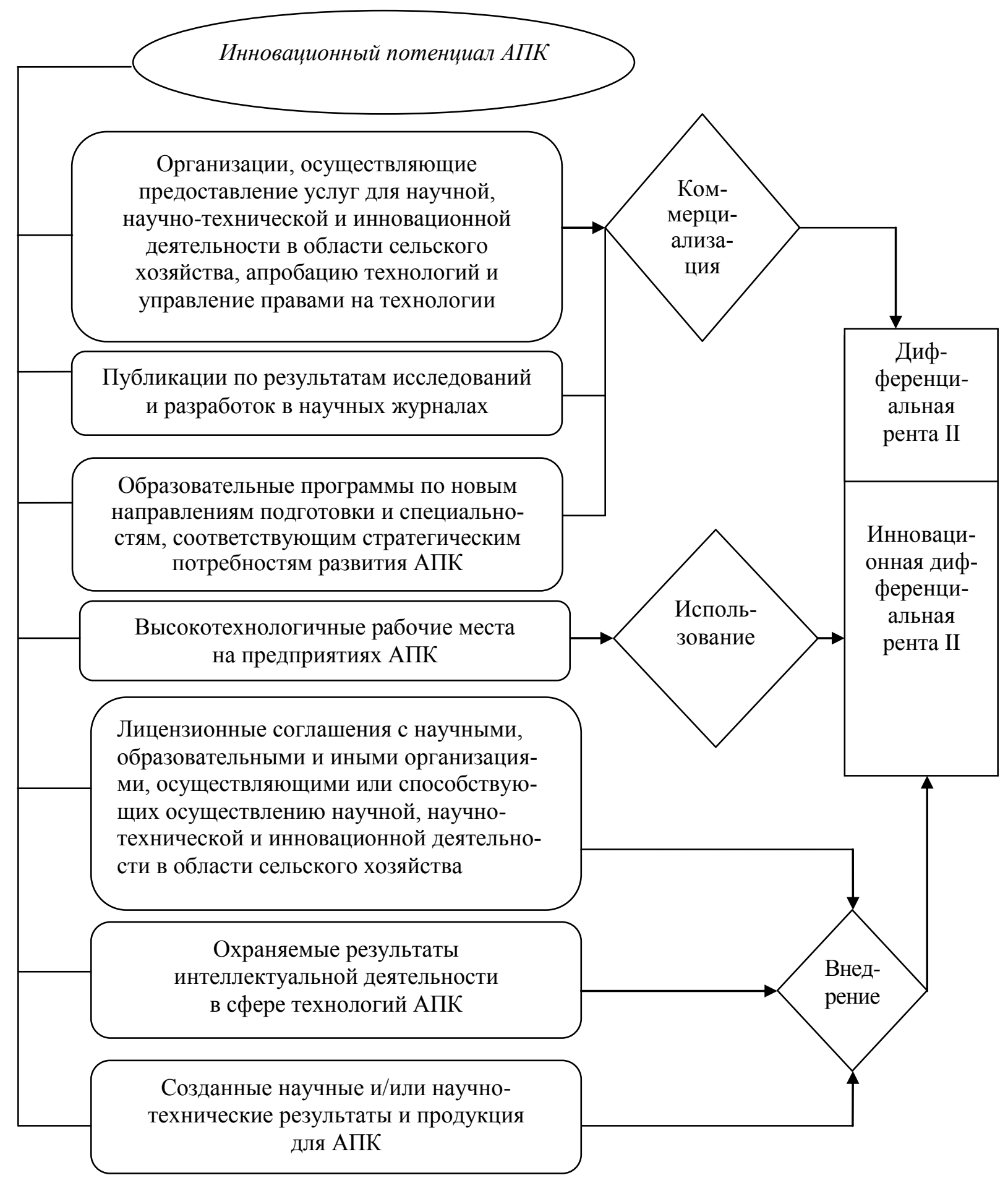

Рис. 4. Формирование инновационной дифференциальной ренты ІІ (разработано автором)

Факторы инновационного потенциала АПК определены автором в соответствии с нормами, установленными Федеральной научно-технической программой развития сельского хозяйства на 2017 - 2025 годы. При использовании концепции формирования инновационной дифференциальной ренты II объектами воздействия при функциональном подходе к управлению инновационном потенциалом являются комплекс согласованных действий по:

- планированию коммерциализации, использования и внедрения факторов формирования инновационного потенциала;

- организации деятельности субъектов инновационной деятельности АПК;

- мотивации субъектов АПК к наращиванию инновационной активности;

- мониторингу и контролю соответствия инновационной деятельности субъектов АПК долгосрочным и среднесрочным национальным, региональным и отраслевым стратегиям социальноэкономического развития. 


\section{Литература}

1. Барсукова Г.Н. Теория земельной ренты как методологическая основа институционального регулирования земельных отношений: исторически экскурс [Электронный журнал] // Политематический сетевой электронный научный журнал Кубанского государственного аграрного университета. 2016. № 124. C. 563-578. URL: https://elibrary.ru/download/elibrary_28103251_78329141.pdf Дата обр. 21.10.2019 г.

2. Белгородская область: совместными усилиями решать новые задачи [Электронный ресурc]. URL: http://mcx.ru/press-service/regions/belgorodskaya-oblast-sovmestnymi-usiliyami-reshat-novyezadachi / Дата обр. 20.12.2019 г.

3. Джалал А.К., Изотова З.А., Бабин М.М. Дифференциальная рента в системе бизнес-планирования деятельности организаций АПК [Электронный ресурс] // Известия сельскохозяйственной науки Тавриды. 2018. № 16 (179). C. 128-137. URL: https://elibrary.ru/download/elibrary_36774240_24350564.pdf Дата обр. 20.12.2019 г.

4. Ефимова Г.А., Осипова О.В. Производственно-генетический потенциал решения проблемы импортозамещения и реиндустриализации АПК РФ [Электронный ресурс] // Экономическое возрождение России. 2015. № 3 (45). C. 117-122. URL: https://elibrary.ru/download/elibrary_24147850_19888741.pdf

5. Жид Ш., Рист Ш. История экономических учений. М.: Экономическое наследие, 1995. 544 с.

6. Капустина Н.B. Методология управления развитием организации на основе риск-менеджмента: автореферат дис. ... доктора экономических наук / Рос. акад. нар. хоз-ва и гос. службы при Президенте РФ. Ростов-на-Дону, 2015. 43 с.

7. Маркс К. Капитал. Т. 3 // Маркс К., Энгельс Ф. Соч., 2-е изд. М.: Издательство политической литературы, 1961-1962. Т. 25. ч. 2, с. 212.

8. Маркс К. Капитал. Критика политической экономии: Т. 2 // К. Маркс, Ф. Энгельс. Соч. - 2-е изд. T. 24.

9. Мещеров В.А. Рыночный механизм рентных отношений в мировой экономике // Экономические науки. 2010. № 11 (72). С. 295 - 306.

10. Носкова E.M. Инновационные технологии в сельском хозяйстве Арктической зоны Российской Федерации // В сборнике: Инновационная экономика и менеджмент: Методы и технологии Сборник материалов II Международной научно-практической конференции. Под ред. О.А. Косорукова, В.В. Печковской, С.А. Красильникова. 2018. С. 226-230.

11. Розенберг Д.И. Комментарии к «Капиталу» К. Маркса. М., 1983. 720 с.

12. Семенов A.C., Дерунова E.A. Моделирование инновационно-технологического развития российской экономики // В сб.: Математическое моделирование в экономике, страховании и управлении рисками Сборник материалов IV Международной молодежной научно-практической конференции: в 2-х томах. 2015. C. 87-92. URL: https://elibrary.ru/download/elibrary_25546193_82050759.pdf Дата обр. 11.10 .2019 г.

13. Сорокин А.В. Деиндустриализация как феномен неравенства норм прибыли // Экономическое возрождение России. 2016. № 3 (49). C. 35-44. URL: https://elibrary.ru/download/elibrary_26607576_33889443.pdf

14. Филатова И.Н. Государственное влияние на инновационное развитие экономики // В сборнике: Математическое моделирование в экономике, страховании и управлении рисками: Сборник материалов IV Международной молодежной научно-практической конференции: в 2-х томах. 2015. C. 257-262. https://elibrary.ru/download/elibrary_25546227_84665505.pdf Дата обр. 17.11.2019 г.

15. Импортозамещение и издержки обращения. Монография / Общ. ред. Третьяк В.П. / Моск. гос. ун-т технологий и упр. им. К.Г. Разумовского (Первый казачий ун-т). М.: Экономика, 2017. 240 с.

Heyfits Boris Igorevich, candidate of economic Sciences, associate Professor, Lipetsk Cossack Institute of technology and management (branch) of the Moscow state University of technology and management named after K.G. Razumovsky (First Cossack University) (4, Krasnoznamennaya St., Lipeck, 398006, Russian Federation). E-mail: b.heifits@yandex.ru

\section{MANAGING THE INNOVATIVE POTENTIAL OF THE AGRO-INDUSTRIAL COMPLEX: A RENT-BASED APPROACH}

\section{Abstract}

The article considers the process of managing the innovative potential of the agro-industrial complex from the point of view of the rent approach. The author studies the impact of Dutch disease on the innovative potential of the agricultural sector, and identifies differences between real and fictitious capital. Studies of the production and genetic potential of solving the problem of import substitution and reindustrialization of the agricultural sector of 
the Russian Federation. As a result, it is proposed to call the excess over the average industry profit in the agricultural sector due to additional capital invested in innovative activities, and the author's idea of the factors that form the innovative differential rent as a result of functional management of the innovative potential of the agricultural sector is formed.

Keywords: innovation potential, agro-industrial complex, rental income, innovative differential income, rental relations, land rent, production competitiveness, labor productivity, organizational and technical innovations.

\section{References}

1. Barsukova G.N. Teoriya zemel'noj renty kak metodologicheskaya osnova institucional'nogo regulirovaniya zemel'nyh otnoshenij: istoricheski ekskurs [Elektronnyj zhurnal] // Politematicheskij setevoj elektronnyj nauchnyj zhurnal Kubanskogo gosudarstvennogo agrarnogo universiteta. 2016. № 124. P. 563-578. URL: https://elibrary.ru/download/elibrary_28103251_78329141.pdf Data obr. 21.10.2019 g.

2. Belgorodskaya oblast': sovmestnymi usiliyami reshat' novye zadachi [Elektronnyj resurs]. URL: http://mcx.ru/press-service/regions/belgorodskaya-oblast-sovmestnymi-usiliyami-reshat-novye-zadachi / Data obr. 20.12.2019 g.

3. Dzhalal A.K., Izotova Z.A., Babin M.M. Differencial'naya renta v sisteme biznes -planirovaniya deyatel'nosti organizacij APK [Elektronnyj resurs] // Izvestiya sel'skohozyajstvennoj nauki Tavridy. 2018. № 16 (179). P. 128-137. URL: https://elibrary.ru/download/elibrary_36774240_24350564.pdf Data obr. 20.12.2019 g.

4. Efimova G.A., Osipova O.V. Proizvodstvenno-geneticheskij potencial resheniya problemy importozameshcheniya i reindustrializacii APK RF [Elektronnyj resurs] // Ekonomicheskoe vozrozhdenie Rossii. 2015. № 3 (45). P. 117-122. URL: https://elibrary.ru/download/elibrary_24147850_19888741.pdf

5. ZHid SH., Rist SH. Istoriya ekonomicheskih uchenij. M.: Ekonomicheskoe nasledie, 1995. 544 p.

6. Kapustina N.V. Metodologiya upravleniya razvitiem organizacii na osnove risk-menedzhmenta: avtoreferat dis. ... doktora ekonomicheskih nauk / Ros. akad. nar. hoz-va i gos. sluzhby pri Prezi-dente RF. Rostov-naDonu, 2015. 43 p.

7. Marks K. Kapital. T. 3 // Marks K., Engel's F. Soch., 2-e izd. M.: Izdatel'stvo politicheskoj lite-ratury, 19611962. T. 25. ch. 2, p. 212.

8. Marks K. Kapital. Kritika politicheskoj ekonomii: T. 2 // K. Marks, F. Engel's. Soch. - 2-e izd. - T. 24.

9. Meshcherov V.A. Rynochnyj mekhanizm rentnyh otnoshenij v mirovoj ekonomike // Ekonomicheskie nauki. 2010. № 11 (72). P. 295 - 306.

10. Noskova E.M. Innovacionnye tekhnologii v sel'skom hozyajstve Arkticheskoj zony Rossijskoj Federacii // V sbornike: Innovacionnaya ekonomika i menedzhment: Metody i tekhnologii Sbornik materialov II Mezhd unarodnoj nauchno-prakticheskoj konferencii. Pod red. O.A. Kosorukova, V.V. Pechkovskoj, S.A. Krasil'nikova. 2018. P. 226-230.

11. Rozenberg D.I. Kommentarii k «Kapitalu» K. Marksa. M., 1983. 720 p.

12. Semenov A.S., Derunova E.A. Modelirovanie innovacionno-tekhnologicheskogo razvitiya rossijskoj ekonomiki // V sb.: Matematicheskoe modelirovanie v ekonomike, strahovanii i upravlenii riskami Sbornik materialov IV Mezhdunarodnoj molodezhnoj nauchno-prakticheskoj konferencii: v 2-h tomah. 2015. P. 8792. URL: https://elibrary.ru/download/elibrary_25546193_82050759.pdf Data obr. 11.10.2019 g.

13. Sorokin A.V. Deindustrializaciya kak fenomen neravenstva norm pribyli // Ekonomicheskoe vozrozhdenie Rossii. 2016. № 3 (49). P. 35-44. URL: https://elibrary.ru/download/elibrary_26607576_33889443.pdf

14. Filatova I.N. Gosudarstvennoe vliyanie na innovacionnoe razvitie ekonomiki // V sbornike: Matematicheskoe modelirovanie v ekonomike, strahovanii i upravlenii riskami: Sbornik materialov IV Mezhdunarodnoj molodezhnoj nauchno-prakticheskoj konferencii: $v \quad 2-\mathrm{h}$ tomah. 2015. P. $257-262$. https://elibrary.ru/download/elibrary_25546227_84665505.pdf Data obr. 17.11.2019 g.

15. Importozameshchenie i izderzhki obrashcheniya. Monografiya / Obshch. red. Tret'yak V.P. / Mosk. gos. un-t tekhnologij i upr. im. K.G. Razumovskogo (Pervyj kazachij un-t). M.: Ekonomika, 2017. 240 p. 